\title{
FONTES DE FÓSFORO PARA ADUBAÇÃO FOLIAR NA CULTURA DO FEIJOEIRO
}

\section{PHOSPHORUS SOURCES TO FOLIAR FERTILIZATION IN COMMON BEAN CROP}

\author{
Adilson PELÁ \\ Marcos Sales RODRIGUES ${ }^{2}$ \\ Jaiciclênia da Silva SANTANA ${ }^{3}$ \\ Itamar Rosa TEIXEIRA ${ }^{4}$
}

\section{RESUMO}

Grande parte do fósforo utilizado nas adubações em solos tropicais é perdida por fixação. A adubação via foliar, por utilizar-se de quantidades bem inferiores às aplicadas ao solo, constitui-se numa importante alternativa para a redução das perdas do elemento por fixação nestes solos. Este trabalho teve como objetivo avaliar o efeito de fontes de fósforo aplicadas via foliar na cultura do feijoeiro, sobre os componentes de produção, a produtividade e a quantidade do nutriente nos grãos. Foi conduzido um experimento em vasos, sob casa-de-vegetação, em delineamento inteiramente casualizado com quatro repetições e seis tratamentos: 1 - adubação completa via solo; 2 - testemunha (sem adubação); aplicação foliar com as fontes: 3 - fosfito de potássio; 4 - ácido fosfórico; 5 -fosfato monoamônico; e 6 - fosfato de potássio. As aplicações foliares de $\mathrm{P}$ foram realizadas semanalmente a partir do sétimo dia após a emergência, na concentração de $10 \mathrm{mg} \mathrm{dm}^{-3}$. A produtividade de grãos com a aplicação de $\mathrm{P}$ foliar foi superior à testemunha, porém inferior à adubação via solo. Não houve diferenças entre as fontes para a produtividade de grãos, mas o fosfato de potássio e o fosfato monoamônico proporcionaram maior acúmulo de $\mathrm{P}$ nos grãos.

Palavras-chave: Phaseolus vulgaris; ácido fosfórico; fosfato monoamônico; fosfato de potássio; fosfito de potássio.

\begin{abstract}
Great part of the phosphorus in the fertilizations tropical soils is lost through fixation. The foliar fertilization, once it uses very lower amounts when compared to the ones applied on soil, it is constituted in an important alternative for the reduction of element losses through fixation in these soils. The objective of this work was to evaluate the applied phosphorus sources to foliar fertilization in commom bean crop, on production components, the grain yield and the amount of the nutrient in the grains. The experiment was carried out in a greenhouse, in pots. The used design was completely randomized with four replications and six treatments: 1- soil fertilization; 2-control treatment (without fertilization); foliar fertilization with the sources 3- potassium phosphite; 4-phosphoric acid; 5-monoammonium phosphate; and 6-potassium phosphate. The $P$ foliar applications were accomplished weekly beginning from the seventh day after the emergence. The grain yield with the $P$ foliar application overcame the witness treatment, but it was inferior the fertilization via soil. The sources were not affected the grain yield, but the potassium phosphate and the monoammonium phosphate provided larger accumulation of $\mathrm{P}$ in the grains. phosphite.

Key-words: Phaseolus vulgaris; monoammonium phosphate; phosphoric acid; potassium phosphate; potassium
\end{abstract}

\footnotetext{
${ }^{1}$ Engenheiro Agrônomo, Doutor em Agronomia, Prof. da Universidade Estadual de Goiás (UEG), Unidade Universitária de Ipameri, GO 330 , Km 241 s/n, Anel Viário, Ipameri-GO, Brasil. CEP 75780-000. E-mail: adilson.pela@ueg.br. Autor para correspondência.

${ }^{2}$ Engenheiro Agrônomo, Mestrando em Agronomia (Ciência do Solo), Faculdade de Ciências Agrárias e Veterinárias - Universidade Estadual Paulista "Júlio de Mesquita Filho" (FCAV-UNESP). Jaboticabal-SP, Brasil. E-mail: agrobytem@gmail.com.

${ }_{3}$ Estudante de Agronomia da Universidade Estadual de Goiás, Unidade Universitária de Ipameri, Ipameri-GO, Brasil. E-mail: jaiciclenia@gmail.com.

${ }^{4}$ Engenheiro Agrônomo, Doutor em Agronomia, Prof. da Universidade Estadual de Goiás, Unidade Universitária de Ipameri, Ipameri-GO, Brasil.

E-mail: itamarrt@yahoo.com.br.
} 


\section{INTRODUÇÃO}

O fósforo é um elemento essencial no metabolismo das plantas, atuando nos processos de transferência de energia da célula, na respiração e na fotossíntese, como componente estrutural dos ácidos nucleicos de cromossomos, assim como de muitas coenzimas, fosfoproteínas e fosfolipídeos (Malavolta, 1980). É um dos elementos que mais contribui para o aumento da produtividade de grãos do feijoeiro, melhorando o desenvolvimento radicular, aumenta o número de vagens e a massa de grãos, ajuda no processo de maturação e qualidade dos mesmos (Fageria et al., 2004).

Embora a necessidade de $P$ requerida seja menor que as quantidades de potássio $(\mathrm{K})$ e de nitrogênio $(N)$ sua aplicação nas culturas ocorrem em doses iguais ou superiores à esses dois elementos (Vieira, 2006a). Isso se deve à elevada taxa de fixação do $P$ em solos tropicais, fazendo com que a maior parte não possa ser utilizada pelas plantas (Vieira, 2006a). Moreira et al. (2006) encontraram correlações positivas entre a capacidade máxima de adsorção de fósforo e teores de ferro total, óxidos de ferro livres e amorfos, constituindo-se nos principais fatores responsáveis pela adsorção do elemento nos solos estudados, e que estão presentes na maioria dos solos tropicais usados na agricultura. Devido a estes problemas o aproveitamento pela cultura adubada é muito baixo, variando de $5 \%$ a $25 \%$ (Vieira, 2006b), fazendo com que seja um dos investimentos mais altos para a prática da agricultura comercial nesses solos (Sousa et al., 2004).

Uma alternativa para minimizar a perda de $P$ por fixação seria através da adubação foliar, possibilitando diminuir o uso de adubos fosfatados, gerando ganhos econômicos e ambientais, pois estes são produzidos a partir de reservas minerais de caráter não renovável. Na planta o $\mathrm{P}$ é um elemento móvel, facilmente redistribuído entre os órgãos, das folhas velhas para as novas, para os frutos e sementes, característica importante para a adubação foliar (Silva, 2006).

A adubação foliar não tem sido muito estudada nos últimos anos, principalmente em relação aos macronutrientes, elementos exigidos em maiores quantidades, sendo utilizada mais para corrigir deficiências ou complementar a nutrição (Mallarino et al., 2001) em períodos de maior demanda destes em algumas culturas. Segundo Alvarenga et al. (2000), a propaganda e a agressividade comercial fizeram com que a prática da adubação foliar se adiantasse à pesquisa. Normalmente o uso de adubação foliar é feito sem embasamento experimental, o que possivelmente leva a não obtenção dos resultados desejados ou esperados de aumento de produção (Rosolem \& Boaretto, 1987). Para Haq \& Mallarino (2000) respostas positivas à fertilização foliar com NPK tendem a ocorrer somente em condições de baixa disponibilidade dos elementos no solo. Suwanvesh \& Morrill (1986) verificaram aumentos na produtividade e na concentração de $\mathrm{P}$ em plantas de amendoim, principalmente em substrato com baixa disponibilidade do elemento. Com fornecimento de enxofre foliar na cultura da soja, Vitti et al. (2007) verificaram que a eficiência de utilização do elemento pelas plantas foi superior à adubação via solo. Carvalho et al. (2001) obtiveram aumentos de produtividade de algodão em caroço com o uso de $\mathrm{N}$ foliar durante oito semanas após $\mathrm{O}$ início do florescimento, mas não para $\mathrm{K}$ ou $\mathrm{N}$ e $\mathrm{K}$. Porém Almeida et al. (2000) verificaram que a adubação nitrogenada via foliar não afetou as características agronômicas e a produtividade do feijoeiro, assim como Oliveira et al. (2006) com a produtividade total, comercial e não-comercial de batata-doce.

Existem alguns dados de pesquisas com o uso de P via foliar. Rezende et al. (2005), utilizandose de adubação foliar com $P$ na cultura da soja, observaram um aumento no rendimento de grãos em até $16 \%$. Kubota et al. (2005) verificaram que a adubação foliar elevou os teores de $P$ nas sementes de feijão quando não se aplicou $P$ ao solo. Aumentos no teor de $\mathrm{P}$ nas sementes de feijoeiros também foram obtidos por Teixeira \& Araújo (1999) com a aplicação via foliar na fase de enchimento das vagens. Muraoka \& Neptune (1981) obtiveram aumentos de produtividade do feijoeiro com a aplicação foliar de soluções de polifosfado de $\mathrm{K}$ e superfosfato triplo. Conte e Castro \& Boareto (2001) verificaram que a adubação foliar não influenciou a qualidade e a produtividade do feijoeiro, porém foi complementar a via solo. Santos (2005) também verificou não haver aumento da produtividade do feijoeiro nas plantas supridas com P via foliar. Já Pelá et al. (2003) obtiveram aumentos lineares nos teores de $P$ na semente, com o número de aplicações foliares do elemento.

No mercado existem diversos produtos para fornecimento de nutrientes via foliar, recentemente desenvolvidos, cuja eficiência necessita de estudos para sua confirmação. É o caso do fosfito de potássio $\left(\mathrm{KH}_{2} \mathrm{PO}_{3}\right)$, que diferentemente das fontes tradicionais do elemento (ácido fosfórico), apresenta maior velocidade de penetração, transporte e redistribuição nas plantas.

Este trabalho teve como objetivo verificar a eficiência de diferentes fontes para o fornecimento via foliar de $\mathrm{P}$ sobre $\mathrm{O}$ desenvolvimento, produtividade e concentração do elemento nos grãos do feijoeiro.

\section{MATERIAL E MÉTODOS}

O experimento foi conduzido em vasos em casa-de-vegetação, na Unidade Universitária de Ipameri-GO, Universidade Estadual de Goiás UEG, no período de agosto de 2006 a julho de 2007. Na sede do município a latitude é de 17운 $\mathrm{S}$, longitude $48^{\circ} 11^{\prime} \mathrm{N}$ e altitude de $800 \mathrm{~m}$. O clima, segundo a classificação de Köppen, é do tipo Aw, constando temperaturas elevadas com chuvas no verão e seca no inverno. 
PELÁ, A. et al. Fontes de fósforo para adubação foliar...

Utilizou-se solo coletado na camada superficial de um Latossolo Vermelho-Amarelo. O mesmo foi submetido à análises químicas, cujos resultados são apresentados na Tabela 1. Realizouse a calagem, utilizando-se calcário dolomítico, visando elevar a saturação por base à $60 \%$, permanecendo o solo incubado por um período de 90 dias após a aplicação do corretivo para completar a reação.

TABELA 1 - Caracterização química do solo antes da instalação do experimento

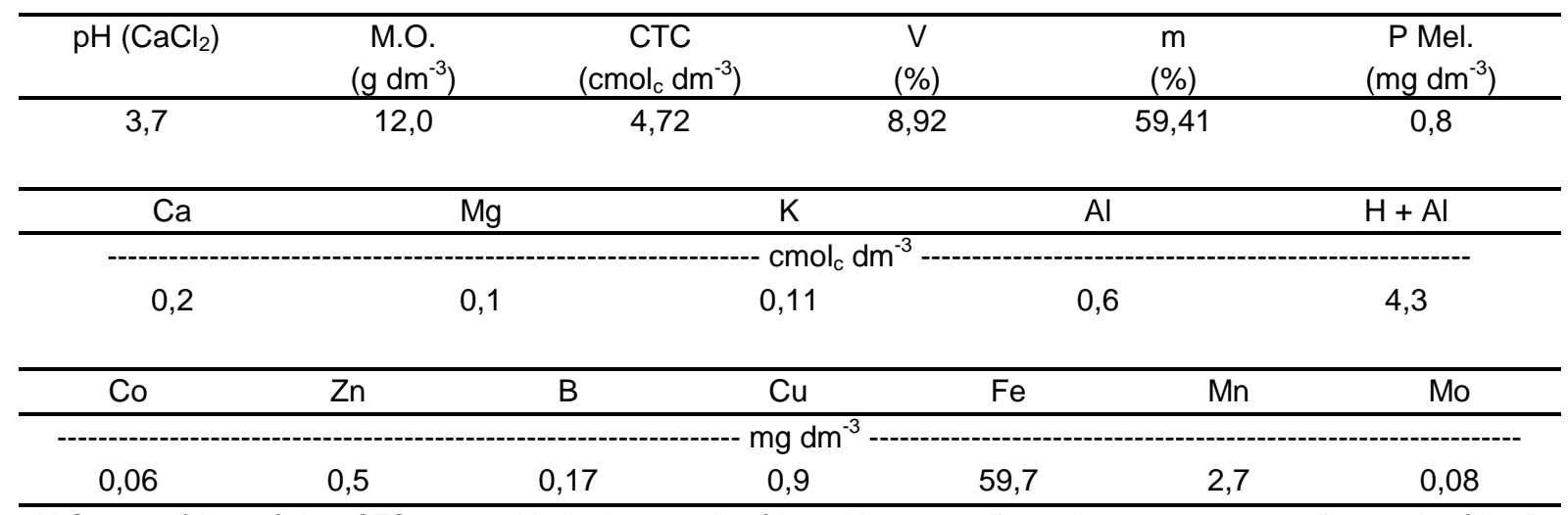

M.O. = matéria orgânica; CTC = capacidade de troca de cátions; $V$ = saturação por bases; $m$ = saturação por alumínio; $P$ Mel. = fósforo extraído pelo método Melich.

Após a incubação o solo foi peneirado a fim de serem preenchidos os vasos. Determinou-se a capacidade máxima de armazenamento de água, pela diferença de massa entre uma amostra umedecida por capilaridade e a massa seca da mesma em estufa (umidade gravimétrica). Os vasos de polietileno de capacidade para sete litros foram preenchidos e então pesados. O resultado foi usado para manter, através de irrigações, o solo a $60 \%$ da capacidade máxima de armazenamento de água.

Utilizou-se 0 delineamento inteiramente casualizado, com seis tratamentos e quatro repetições. Os tratamentos foram constituídos por: $\mathrm{T} 1$ - fosfito de potássio $\left(\mathrm{KH}_{2} \mathrm{PO}_{3}\right) ; \mathrm{T} 2$ - ácido fosfórico $\left(\mathrm{H}_{3} \mathrm{PO}_{4}\right)$; T3 - fosfato monoamônico-MAP $\left(\mathrm{NH}_{4} \mathrm{H}_{2} \mathrm{PO}_{4}\right) ; \mathrm{T} 4$ - fosfato de potássio $\left(\mathrm{KH}_{2} \mathrm{PO}_{4}\right) ; \mathrm{T} 5$ - adubação completa via solo; T6 - testemunha sem adubação. Nos tratamentos T1 a T4 foram realizadas seis pulverizações foliares, aos $7 ; 14 ; 21$; 28; 35 e 42 dias após a emergência (DAE). As seis aplicações foram realizadas com o objetivo de evitar o uso de soluções mais concentradas, que podem causar danos ás folhas pelo efeito salino. As épocas de aplicação foram definidas com base na marcha de absorção de $\mathrm{P}$, pois conforme resultados obtidos por Haag \& Malavolta (1967), 73,6\% do P é absorvido até 50 dias após a germinação. A aplicação foliar de $\mathrm{P}$ foi realizada com borrifador, protegendo-se o solo do vaso com papel alumínio para evitar que os produtos atingissem o solo e fossem absorvidos pelas raízes. As soluções foram preparadas com produtos PA (puro para análise) com concentração de $10 \mathrm{mg}$ de $\mathrm{P} \mathrm{dm} \mathrm{dm}^{-3}$ de solução. As soluções foram balanceadas devido a presença de outros nutrientes em algumas fórmulas, como o $\mathrm{K}$ ou o N. Para o balanceamento foi utilizados a uréia $\left(450 \mathrm{~g} \mathrm{~kg}^{-1}\right.$ de $\left.\mathrm{N}\right)$ como fonte de $\mathrm{N}$ e o cloreto de potássio $\left(600 \mathrm{~g} \mathrm{~kg}^{-1}\right.$ de $\mathrm{K}_{2} \mathrm{O}$ ) como fonte de $\mathrm{K}$. Foram borrifados, utilizando-se borrifador graduado,
$5 \mathrm{~cm}^{3}$ da solução em cada vaso nas primeiras quatro aplicações; na quinta e sexta aplicações borrifou-se $7,5 \mathrm{~cm}^{3}$ devido a presença de maior área foliar.

A adubação no solo consistiu da aplicação de $120 \mathrm{mg} \mathrm{dm}^{-3}$ de $\mathrm{K}$, usando-se como fonte cloreto de potássio $\left(600 \mathrm{~g} \mathrm{~kg}^{-1}\right.$ de $\mathrm{K}_{2} \mathrm{O}$ ) e $30 \mathrm{mg} \mathrm{dm}^{-3}$ de $\mathrm{N}$ na forma de uréia (450 $\mathrm{g} \mathrm{kg}^{-1}$ de $\mathrm{N}$ ) para os tratamentos $\mathrm{T} 1$ ao $\mathrm{T} 5$. O tratamento $\mathrm{T} 5$ recebeu ainda uma dose de $120 \mathrm{mg} \mathrm{dm}^{-3}$ de $\mathrm{P}$ na forma de superfosfato simples $\left(200 \mathrm{~g} \mathrm{~kg}^{-1}\right.$ de $\left.\mathrm{P}_{2} \mathrm{O}_{5}\right)$. Foram realizadas duas adubações de cobertura com 30 $\mathrm{mg} \mathrm{dm}^{-3}$ de $\mathrm{N}$, na forma de uréia $\left(450 \mathrm{~g} \mathrm{~kg}^{-1}\right.$ de $\left.\mathrm{N}\right)$, aos 19 e 48 dias após a emergência das plantas. Uma solução contendo micronutrientes, com 216;

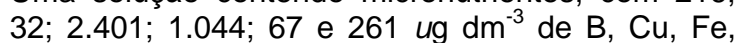
$\mathrm{Mn}, \mathrm{Mo}$, e $\mathrm{Zn}$ respectivamente, foi aplicada no solo dos vasos aos 48 DAE, num volume de $0,1 \mathrm{dm}^{3}$ vaso $^{-1}$.

Utilizando-se sementes de feijão da cultivar Pérola, tratadas com uma solução de $0,1 \mathrm{~cm}^{3} \mathrm{dm}^{-3}$ de hipoclorito de sódio, realizou-se a semeadura, distribuindo-se seis sementes por vaso, em forma de círculo, na parte central do mesmo. Posteriormente foi realizado o desbaste, cinco dias DAE, deixando-se três plantas por vaso.

Aos doze DAE foi realizada a aplicação do fungicida/acaricida Mancozebe, na proporção de 1,6 $\mathrm{g}$ do ingrediente ativo $\mathrm{dm}^{-3}$, de maneira preventiva à ocorrência de doenças fúngicas.

A colheita foi feita de maneira escalonada, de acordo com a presença de vagens secas, realizando-se a última aos $103 \mathrm{DAE}$. A parte aérea foi coletada e levada a estufa a $60 \stackrel{\circ}{\mathrm{C}}$ até atingir peso constante e então pesada para determinação de massa seca. Determinou-se também o número de vagens por planta, o número de grãos por vagens e a produtividade de grãos por vaso. Posteriormente os grãos foram submetidos à 
PELÁ, A. et al. Fontes de fósforo para adubação foliar...

análise química para determinação do teor de fósforo, conforme descrito em Bataglia et al. (1983). O $\mathrm{P}$ acumulado nos grãos vaso- ${ }^{-1}$ foi obtido multiplicando-se o teor de $\mathrm{P}$ nos grãos pela massa seca dos mesmos por vaso. Ao tratamento com fósforo via solo foi atribuído o valor de $100 \%$ para o teor de $\mathrm{P}$ acumulado nos grãos vaso ${ }^{-1}$; e para os demais tratamentos dividiu-se o teor acumulado nos grãos em cada tratamento pelo valor de $\mathrm{P}$ acumulado nos grãos obtido com a adubação via solo, multiplicando-se por 100 .

Os dados foram submetidos ao teste de Tukey a $5 \%$ de probabilidade para a comparação entre médias.

\section{RESULTADOS E DISCUSSÃO}

O número de vagens por planta foi maior no tratamento que recebeu adubação completa via solo (T5), que produziu 6,16 vagens por planta, diferindo significativamente da testemunha (T6) e das fontes de $\mathrm{P}$ fosfito de potássio e ácido fosfórico (T1 e T2 respectivamente), não diferindo, porém, das fontes fosfato monoamônico e fosfato de potássio (T3 e T4 respectivamente) (Tabela 2). A testemunha foi inferior a todos os tratamentos, produzindo em média uma vagem por planta, o que significa que a aplicação de $P$ via foliar, independente da fonte, proporcionou incrementos significativos em relação a não aplicação de $P$ no solo. Aumentos no número de vagens por planta também foram encontrados por Zucareli et al. (2006), com o aumento das doses de P no solo. Segundo Fageria et al. (2004), o P aumenta o número de vagens por planta. De acordo com Zucareli et al. (2006), o número de vagens é o componente de produção que mais contribui com o aumento de produtividade na cultura do feijoeiro, sendo diretamente influenciado pelas condições do meio, entre elas a adubação com $P$ via solo ou foliar.

TABELA 2 - Número de vagens por planta, número de grãos por vagens, massa seca de grãos e de parte aérea, e teor de fósforo nos grãos em função de fontes para o fornecimento de fósforo via foliar na cultura do feijoeiro.

\begin{tabular}{|c|c|c|c|c|c|}
\hline Tratamentos & Vagem planta $^{-1}$ & Grãos vagem $^{-1}$ & MS. Grãos & MS. PA. & $\begin{array}{c}\text { Fósforo } \\
\text { grãos }\end{array}$ \\
\hline & \multicolumn{2}{|c|}{----------------- Unidades ---------------- } & \multicolumn{2}{|c|}{----------- g vaso-1 -------- } & $\mathrm{g} \mathrm{kg}^{-1}$ \\
\hline Fosfito de potássio & $4,34 \mathrm{~b}$ & 3,00 & $10,11 b$ & $10,77 \mathrm{ab}$ & $2,59 \mathrm{bc}$ \\
\hline Ácido fosfórico & $4,42 \mathrm{~b}$ & 3,30 & $10,69 \mathrm{~b}$ & $10,42 \mathrm{~b}$ & $3,13 \mathrm{bc}$ \\
\hline Fosfato monoamônico & $4,75 a b$ & 3,00 & $10,50 \mathrm{~b}$ & $10,95 a b$ & $3,56 \mathrm{~b}$ \\
\hline Fosfato de potássio & $4,83 a b$ & 2,88 & $9,65 b$ & $9,79 \mathrm{~b}$ & $5,00 \mathrm{a}$ \\
\hline Via solo & 6,16 a & 3,56 & $16,10 \mathrm{a}$ & $12,80 \mathrm{a}$ & $2,08 \mathrm{c}$ \\
\hline Testemunha & $1,00 \mathrm{c}$ & 3,17 & $2,23 c$ & $2,08 \mathrm{c}$ & $2,51 \mathrm{bc}$ \\
\hline D.M.S. & 1,65 & 1,28 & 2,75 & 2,37 & 1,22 \\
\hline CV. (\%) & 17,30 & 18,01 & 12,39 & 11,14 & 17,02 \\
\hline
\end{tabular}

MS. - Massa seca; PA. - Parte aérea; D.M.S. - Desvio Médio Significativo. CV. - Coeficiente de variação. Médias com a mesma letra na coluna não diferem entre si a $5 \%$ pelo teste Tukey.

Não houve diferença significativa entre os tratamentos quanto ao número de grãos por vagem (Tabela 2), indicando que essa característica é determinada geneticamente e, portanto, sofrendo pouca interferência do meio. Esses resultados estão de acordo com os obtidos por Zucareli et al. (2006), que também não encontraram diferenças significativas de doses de $\mathrm{P}$ no solo sobre o número total de lóculos, de lóculos cheios e de lóculos vazios em vagens de feijão.

$\mathrm{O}$ fornecimento de $\mathrm{P}$ via solo proporcionou uma produção de $12,80 \mathrm{~g}$ de massa seca da parte aérea por vaso, superior às fontes ácido fosfórico, fosfato de potássio e testemunha, que produziram em média 10,$42 ; 9,79$ e $2,08 \mathrm{~g}$ por vaso, respectivamente (Tabela 2 ). A testemunha foi estatisticamente inferior a todos os tratamentos. Isso ocorreu devido ao papel do $\mathrm{P}$ na fotossíntese e, consequentemente, no acúmulo de massa seca, e mostra que mesmo via foliar houve benefícios em relação a não aplicação deste. Não houve diferenças significativas entre as fontes de $\mathrm{P}$ em relação à produção de massa seca da parte aérea. Aumentos na massa seca de parte aérea do feijoeiro foram obtidos também por Souza et al. (2006), em resposta a aplicação de calcário e matéria orgânica, que reduziu a fixação do $P$ no solo aumentou sua disponibilidade às plantas.

Quanto à variável massa seca de grãos por vaso, a adubação via solo, com $16,10 \mathrm{~g}$, foi superior a todos os tratamentos. Não houve diferença significativa entre as fontes de fósforo aplicadas via foliar, porém todas mostraram-se superiores à testemunha, que produziu em média 2,23 g por vaso, enquanto que com a adubação foliar os valores variaram de 9,65 a $10,69 \mathrm{~g}$ por vaso (Tabela 2). A massa seca de grãos por vaso apresentou comportamento semelhante ao número 
PELÁ, A. et al. Fontes de fósforo para adubação foliar...

de vagens por planta, confirmando os resultados obtidos para este componente de produção. Esses resultados discordam dos obtidos por Rezende et al. (2005), na cultura da soja, por Muraoka \& Neptune (1981) e por Pelá et al. (2003) com a cultura do feijoeiro. Porém, são concordantes aos obtidos por Conte e Castro \& Boareto (2001) e Santos (2005), que verificaram que a adubação foliar não influenciou a produtividade do feijoeiro. Essas divergências nos resultados provavelmente ocorrem em função de condições distintas em que cada experimento foi realizado, como fertilidade do solo, concentração da solução, fases da cultura no momento da aplicação, condições climáticas, volume dos vasos, modo de aplicação, entre outros.

Maior concentração de fósforo nos grãos foi obtida com a fonte fosfato de potássio, com 5,00 $\mathrm{g} \mathrm{kg}^{-1}$, que diferiu significativamente dos demais tratamentos (Tabela 2). O uso de fosfato monoamônico também proporcionou concentração de $3,56 \mathrm{~g} \mathrm{~kg}^{-1}$, superior à aplicação via solo, com $2,08 \mathrm{~g} \mathrm{~kg}^{-1}$. A baixa concentração com 0 fornecimento de $P$ via solo pode ter sido em função do efeito de diluição que, segundo Malavolta (1980), ocorre quando há um maior crescimento ou produção da planta, hipótese esta confirmada nos parâmetros massa seca de parte aérea e dos grãos do feijoeiro (Tabela 2). Também pode ter ocorrido consumo de luxo, a exemplo dos resultados obtidos por Soares et al. (2007), que verificaram aumentos nos teores de $\mathrm{P}$ na parte aérea de sorgo com a maior dose de fosfato, sem reflexos proporcionais na produção de matéria seca.

O fosfato potássio foi a fonte que proporcionou o maior acúmulo de $\mathrm{P}$ nos grãos vaso 1 , com 48,46 mg vaso-1 (Tabela 3), não diferindo significativamente do fosfato monoamônico e do fornecimento via solo, com 37,19 e 33,66 mg vaso $^{-1}$, respectivamente. Porém, foi superior às fontes ácido fosfórico, fosfito de potássio e testemunha, cujos conteúdos de $\mathrm{P}$ acumulados foram $26,64,32,81$ e $5,42 \mathrm{mg}$ por vaso, correspondente a $97,75 \%, 79,25 \%$ e $16,00 \%$ em relação ao fornecimento via solo. A testemunha foi inferior a todos os tratamentos, tanto em relação ao conteúdo total por vaso quanto ao valor relativo. Corroboram com esses resultados os obtidos por Teixeira \& Araújo (1999), e Pelá et al. (2003), que também verificaram aumentos nos teores de $P$ nos grãos. Isso evidencia a absorção foliar e o translocamento do nutriente da folha para o grão que, segundo Malavolta (1980), é um elemento de alta mobilidade na planta. Isso pode contribuir para melhorar o vigor das sementes e/ou seu valor nutricional. Lima et al. (2003), porém, não verificaram diferenças significativas na qualidade fisiológica de sementes de café em função de várias combinações de nutrientes fornecidos via foliar no período de florescimento da cultura.

TABELA 3 - Fósforo acumulado nos grãos do feijoeiro $\left(\mathrm{mg} \mathrm{vaso}^{-1}\right.$ ) e em relação ao fornecimento via solo (\%).

\begin{tabular}{|c|c|c|}
\hline \multirow[b]{2}{*}{ TRATAMENTOS } & \multicolumn{2}{|c|}{$\mathrm{P}$ acumulado nos grãos } \\
\hline & $\mathrm{mg} \mathrm{vaso}^{-1}$ & $\begin{array}{l}\text { \% em relação ao fornecimento via } \\
\text { solo }\end{array}$ \\
\hline Fosfito de potássio & $26,64 \mathrm{~b}$ & $79,25 b$ \\
\hline Ácido fosfórico & $32,81 \mathrm{~b}$ & $97,75 \mathrm{~b}$ \\
\hline Fosfato monoamônico & $37,19 a b$ & $110,50 a b$ \\
\hline Fosfato de potássio & $48,46 \mathrm{a}$ & $144,00 \mathrm{a}$ \\
\hline Via solo & $33,66 a b$ & $100,00 a b$ \\
\hline Testemunha & $5,42 \mathrm{c}$ & $16,00 \mathrm{c}$ \\
\hline D.M.S. & 15,55 & 46,05 \\
\hline C.V. & 22,53 & 22,45 \\
\hline
\end{tabular}

D.M.S. - Desvio Médio Significativo. CV. - Coeficiente de variação. Médias com a mesma letra na coluna não diferem entre si a $5 \%$ pelo teste Tukey.

\section{CONCLUSÕES}

1) A adubação via solo proporcionou a maior produtividade de grãos. Não houve diferença entre as fontes de $\mathrm{P}$ aplicadas via foliar quanto à esse fator, porém todas superaram a testemunha.

2) Maior quantidade de $P$ acumulada nos grãos foi obtida com a fonte fosfato de potássio, seguida pelo fosfato monoamônico e pelo fornecimento via solo.

\section{AGRADECIMENTOS E CONFLITOS DE INTERESSES}

Ao Conselho Nacional de Desenvolvimento Científico e Tecnológico (CNPq) pelo apoio através da concessão de bolsa.

O presente trabalho não apresenta conflitos de interesses que sejam do conhecimento dos autores. 
PELÁ, A. et al. Fontes de fósforo para adubação foliar...

\section{REFERÊNCIAS}

1. ALMEIDA, C. de. et al. Uréia em cobertura e via foliar em feijoeiro. Scientia Agricola, v. 57, n. 2, p. 293-298, 2000.

2. ALVARENGA, M. A. R. et al. Efeito de doses de nitrogênio aplicadas no solo e níveis de cálcio aplicados via foliar sobre o teor e o acúmulo de micronutrientes em alface americana. Ciência e Agrotecnologia, v. 24, n. 4, p. 905-916, 2000.

3. BATAGLIA, O. C. et al. Métodos de análise química de plantas. Campinas: Instituto Agronômico de Campinas, 1983. 48 p. (Boletim Técnico, 78).

4. CARVALHO, M. A. C. et al. Uso da adubação foliar nitrogenada e potássica no algodoeiro. Bragantia, v. 60, n. 3, p. 239 244, 2001.

5. CONTE E CASTRO, A. M.; BOARETTO, A. E. Adubação foliar do feijoeiro com nutrientes, vitamina b1 e metionina. Scientia Agraria, v. 2, n. 1-2, p. 117-121, 2001

6. FAGERIA, N. K.; BARBOSA FILHO, M. P.; STONE, L. F. Nutrição de fósforo na produção de feijoeiro. In: YAMADA, T.; ABDALLA, S. R. S. (Ed.). Fósforo na agricultura brasileira. Piracicaba: POTAFÓS, 2004. cap. 17, p. 435-456.

7. HAAG, H. P.; MALAVOLTA, E. Absorção de nutrientes pela cultura do feijoeiro. Bragantia, v. 26, n. 30, p. 381-391, 1967.

8. HAQ, M. U.; MALLARINO, A. P. Soybean yield and nutrient composition as affected by early season foliar fertilization. Agronomy Journal, v. 92, n. 1, p. 16-24, 2000.

9. KUBOTA, F. Y. et al. Aumento dos teores de fósforo e de molibdênio em sementes de feijoeiro via adubação foliar. In: CONGRESSO NACIONAL DE PESQUISA DE FEIJÃO, 8., 2005, Goiânia. Anais... Santo Antônio de Goiás: Embrapa Arroz e Feijão, 2005. v. 2. p. 673-676.

10. LIMA, D. M. et al. Efeito da adubação foliar no cafeeiro, em sua produção e na qualidade de suas sementes. Ciência e Agrotecnologia, p. 1499-1505, 2003. Edição Especial.

11. MALAVOLTA, E. Elementos de nutrição mineral de plantas. São Paulo: Agronômica Ceres, 1980. 254 p.

12. MALLARINO, A. P. et al. Variation in soybean response to early season foliar fertilization among and within fields. Agronomy Journal, v. 93, n. 6, p. 1220-1226, 2001.

13. MOREIRA, F. L. M. et al. Adsorção de fósforo em solos do Estado do Ceará. Revista Ciência Agronômica, v. 37, n. 1, p. 7-12, 2006

14. MURAOKA, T.; NEPTUNE, A. M. L. Efeito da aplicação foliar de polifosfato, superfosfato, uréia e yogen na produção do feijoeiro (Phaseolus vulgaris L.). In: SIMPÓSIO DE ADUBAÇÃO FOLIAR, 1., 1981, Botucatu. Anais... Botucatu: FEPAF, 1981. p. 120

15. OLIVEIRA, A. P. et al. Produção de raízes de batata-doce em função do uso de doses de $\mathrm{N}$ aplicadas no solo e via foliar. Horticultura Brasileira, v. 24, n. 3, p. 279-282, 2006.

16. PELÁ, A. et al. Aplicação de fósforo via foliar durante o desenvolvimento do feijoeiro. In: CONGRESSO BRASILEIRO DE CIÊNCIA DO SOLO, 29., 2003, Ribeirão Preto. Anais... Ribeirão Preto: [s. n.], 2003. 1 CD-ROM.

17. REZENDE, P. M. de. et al. Adubação foliar. I. Épocas de aplicação de fósforo na cultura da soja. Ciência e Agrotecnologia, v. 29, n. 6, p. 1105-1111, 2005.

18. ROSOLEM, C. A.; BOARETTO, A. E. Adubação foliar do feijoeiro. In: SIMPÓSIO BRASILEIRO DE ADUBAÇÃO FOLIAR, 2., Botucatu, 1987. Anais... Campinas: Fundação Cargill, 1987. p. 449-512.

19. SANTOS, M. G. Aplicação foliar de fósforo, metabolismo fotossintético e produtividade do feijoeiro comum sob déficit hídrico. 2005. $74 \mathrm{f}$. Tese (Doutorado em Fitotecnia) - Escola Superior de Agricultura "Luiz de Queiroz", Universidade de São Paulo, Piracicaba, 2005.

20. SILVA, P. R. C. Processo de produção de adubos foliares. Salvador: Serviço Brasileiro de Respostas Técnicas (Rede de Tecnologia da Bahia), 2006. 5 p.

21. SOARES, I.; LIMA, S. C.; CRISÓSTOMO, L. A. Crescimento e composição mineral de mudas de gravioleira em resposta a doses de fósforo. Revista Ciência Agronômica, v. 38, n. 4, p. 343-349, 2007.

22. SOUSA, D. M. G.; LOBATO, E.; REIN, T. A. Adubação com fósforo. In: SOUSA, D. M. G.; LOBATO, E. (Ed.). Cerrado: correção de solo e adubação. 2. ed. Brasília: Embrapa Cerrados, 2004. cap. 6, p.147-167.

23. SOUZA, R. F. et al. Nutrição fosfatada e rendimento do feijoeiro sob influência da calagem e adubação orgânica. Ciência e Agrotecnologia, v. 30, n. 4, p. 656-664, 2006.

24. SUWANVESH, T.; MORRILL, L. G. Foliar application of phosphorus to spanish peanuts. Agronomy Journal, v. 78, n. 1, p. 54-58, 1986

25. TEIXEIRA, M. G.; ARAÚJO, A. P. Aumento do teor de fósforo em sementes de feijoeiro através da adubação foliar. In: REUNIÃO NACIONAL DE PESQUISA DE FEIJÃO, 6., Salvador, 1999. Anais... Santo Antônio de Goiás: Embrapa Arroz e Feijão, 1999. p. 756-759.

26. VIEIRA, C. Adubação mineral e calagem. In: VIEIRA, C.; PAULA JÚNIOR, T. J.; BORÉM, A. Feijão. 2. ed. Viçosa: Universidade Federal de Viçosa, 2006a. p. 115-142.

27. VIEIRA, R. F. Fundamentos da quimigação e fertigação. In: VIEIRA, C.; PAULA JÚNIOR, T. J.; BORÉM, A. Feijão. 2. ed. Viçosa: Universidade Federal de Viçosa, 2006b. p. 213-258.

28. VITTI, G. C. et al. Assimilação foliar de enxofre elementar pela soja. Pesquisa Agropecuária Brasileira, v. 42, n. 2, p. 225-229, 2007.

29. ZUCARELI, C. et al. Adubação fosfatada, componentes de produção, produtividade e qualidade fisiológica em sementes de feijão. Revista Brasileira de Sementes, v. 28, n. 1, p. 9-15, 2006.

Recebido em 21/11/2008 Aceito em 11/05/2009 